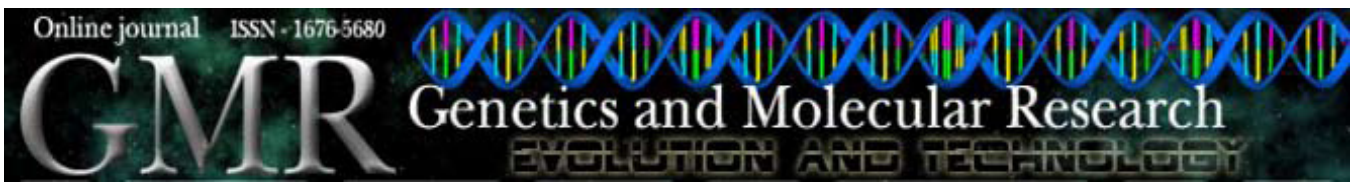

\title{
Molecular and chromosomal mutations among children with B-lineage lymphoblastic leukemia in Brazil's Federal District
}

\author{
D.R. Mesquita ${ }^{1,6}$, J.C. Córdoba ${ }^{2}$, ÍQ. Magalhães ${ }^{2}$, M.S. Córdoba ${ }^{2,3}$, \\ J.R.C. Oliveira ${ }^{2}$, A. Gonçalves ${ }^{4}$, I. Ferrari ${ }^{3,5}$ and C. Martins-de-Sá ${ }^{6}$ \\ ${ }^{1}$ Diretoria de Ensino de Graduação, \\ Centro Federal de Educação Tecnológica do Amazonas, Manaus, AM, Brasil \\ ${ }^{2}$ Núcleo de Oncologia e Hematologia Pediátrica, \\ Hospital de Apoio de Brasília, Secretaria de Saúde do DF, \\ Brasília, DF, Brasil \\ ${ }^{3}$ Serviço de Genética Clínica, Hospital Universitário de Brasília, \\ Universidade de Brasília, Brasília, DF, Brasil \\ ${ }^{4}$ Grupo de Saúde Coletiva e Atividade Física, \\ Faculdade de Educação Física, Universidade de Campinas, \\ Campinas, SP, Brasil \\ ${ }^{5}$ Departamento de Genética e Morfologia, \\ Instituto de Ciências Biológicas, Universidade de Brasília, \\ Brasília, DF, Brasil \\ ${ }^{6}$ Departamento de Biologia Celular do Instituto de Ciências Biológicas, \\ Universidade de Brasília, Brasília, DF, Brasil \\ Corresponding author: C. Martins-de-Sá \\ E-mail: sasa@unb.br
}

Genet. Mol. Res. 8 (1): 345-353 (2009)

Received January 13, 2009

Accepted February 4, 2009

Published March 24, 2009

ABSTRACT. Acute lymphoblastic leukemia (ALL) accounts for approximately $80 \%$ of all acute leukemias during childhood. Chromosomal anomalies resulting from gene fusion, which are frequent in leukemias, create hybrid transcripts, the great majority of which encode transcription factors. We analyzed 88 pediatric patients (median age 7.3 years) who had B-lineage acute lymphoblastic leukemia (B-ALL), using reverse tran- 
scriptase-polymerase chain reaction, to look for gene fusion transcripts of $T E L / A M L 1, E 2 A / P B X 1, B C R / A B L \mathrm{p} 190$, and $M L L / A F 4$. The frequencies of these transcripts were $21.21,9.68,3.03$, and $0 \%$, respectively. All positive cases had a common B-ALL immunophenotype. The low frequency of the TEL/AML1 transcript that is found in developing countries, such as Brazil, may be due to the low incidence of leukemia; this would support Greaves' hypothesis.

Key words: Acute lymphoblastic leukemia; Cytogenetics; Reverse transcriptase-polymerase chain reaction; Chromosomal anomalies; Hybrid transcripts

\section{INTRODUCTION}

Acute leukemias comprise a heterogeneous group of hematologic neoplasias in which there is clonal proliferation of myeloid or lymphoid cells; they occur in adults as well as children, although at different frequencies (Zago et al., 2001). In patients under 15 years old, they account for over $30 \%$ of all malignant diseases (Pui et al., 2008). Acute lymphoblastic leukemia (ALL) accounts for approximately $80 \%$ of all acute leukemia in childhood, contrasting with about $20 \%$ of the cases in adults (Pui and Crist, 1994).

In B-lineage ALL (B-ALL) among children, the most prevalent chromosomal mutation is the $\mathrm{t}(12 ; 21)$ translocation, which causes TEL/AML1 gene fusion, and hyperdiploidy. Both show evidence of prenatal origins (Wiemels et al., 1999), occur in approximately $25 \%$ of cases (van Dongen et al., 1999) and confer a good prognosis (Rubnitz and Look, 1999). This disease's common form, which includes all variations of TEL/AML1 fusion, has a low incidence in developing countries, which supports the hypothesis that this cancer may be associated with a better quality of life and perhaps with modified infection patterns in childhood (Greaves, 1988; Magalhães et al., 2000). According to Greaves, the absence or reduction of common infections during the first year of life may favor immunological stress when confronting these infections later in life. This phenomenon would lead to a second molecular event, necessary to promote the malignant process, explaining the peak in ALL among children of 2 to 5 years of age (Greaves, 1988).

The recurrent rearrangements associated with poor prognosis occur at a lower frequency: $\mathrm{t}(1 ; 19) E 2 A / P B X 1$, present in 5 to $6 \%$ of cases (van Dongen et al., 1999; Raimond, 1999); p190 type $\mathrm{t}(9 ; 22) B C R / A B L$, in 3 to $5 \%$ (Raimond, 1999; Sastre et al., 2007), and $\mathrm{t}(4 ; 11) M L L / A F 4$, detected in 2 to $5 \%$ of pediatric B-ALL cases (Pui et al., 1990; van Dongen et al., 1999) and in over 50 to $85 \%$ of B-ALL cases among unweaned infants (van Dongen et al., 1999; Emerenciano et al., 2007).

In this research, cytogenetic studies were carried out along with molecular analyses by reverse transcriptase-polymerase chain reaction (RT-PCR) in 88 pediatric patients with BALL, consecutively admitted in the Oncological and Hematological Pediatric Service (NOHPSESDF) at the Hospital de Apoio de Brasília (HAB), from 2005 to 2007. The respective results are presented here to: i) report, for the first time in Brazil's Federal District, the frequency observed in recurrent rearrangements in pediatric B-ALL; ii) explore the association between molecular and cytogenetic characterization of these mutations, and iii) correlate these sets of data in order to gain a better understanding of the disease in nonindustrialized countries. 


\section{MATERIAL AND METHODS}

\section{Reference population and study group}

The reference population in this study was made up of all the children and adolescents less than 18 years of age and diagnosed with B-ALL, consecutively admitted by the NOHPSESDF team, from January 2005 to December 2007. Of a total of 170 pediatric patients, with an initial clinical-laboratory diagnosis of leukemia registered in that period, $102(60 \%)$ presented B-ALL, of which 14 were excluded due to insufficient quantity of material for molecular analyses (13) and RNA degradation (1), resulting in a group consisting of 88 patients $(86.27 \%)$.

Given the fact that HAB is the regional benchmark in public health treatment of infant leukemias, this service covers all leukemia cases handled by the Federal District's public network, which includes pediatric patients from the Federal District and its outlying areas. The Hospital also attends pediatric cases from other states in Brazil, especially Goiás, Minas Gerais and Bahia, estimated to account for $5 \%$ of the pediatric hematology/oncology cases.

\section{Samples and techniques}

Samples taken from the bone marrow of each patient were sent to the Genetics Unit at the Hospital de Apoio in Brasília, where immunophenotyping was carried out to identify the lineage and differentiation level of the leukemia cells. In the course of the project, a subsample of 44 cases was submitted to cytogenetic analysis both to provide more complete information on the specific rearrangement, and also to identify numerical chromosomal mutations.

For the molecular analysis, bone marrow (86) or peripheral blood (4) samples were sent to the Gene Biology Laboratory of the Cell Biology Department of the University of Brasília. This technique was carried out to detect hybrid transcripts and identify the occurrence of the recurrent rearrangements $(B C R / A B L, M L L / A F 4, E 2 A / P B X 1$, and TEL/AML1). Regarding this last procedure, specimens from 80 patients were analyzed only at the time of diagnosis, six only during relapse and two at diagnosis and in relapse. Of the 90 samples analyzed, 54 had been cryopreserved. A patient with constitutional trisomy 21 was included.

Written informed consent was obtained from patients or their legal guardians, and all studies were approved by the institutional review board at each collaborating site.

\section{Immunophenotyping}

The leukemic cells were immunophenotyped using monoclonal antibodies to define the lineage and to determine the level of differentiation. Antigen expression was determined by indirect immunofluorescence (BD, FACS Calibur) evaluated by flow cytometry (Catovsky et al., 1991). The default panel established included: sCD34, sCD45, sHLA-Dr, sCD117, sCD10, sCD4, sCD7, sCD8, sCD19, sCD38, and $\mathrm{cCD} 13$, cMPO, cTdt, cCD2, cCD3, cCD22, and cCD79a. The reactivity of cells was considered to be positive starting at 20\% (CellQuest).

\section{Cytogenetic analysis}

To obtain metaphase chromosomes, two cultures were grown in $\mathrm{GIBCO}^{\circledR}$ RPMI 
Media 1640 and $\mathrm{GIBCO}^{\circledR}$ fetal bovine serum, both incubated at $37^{\circ} \mathrm{C}$ and submitted to treatment with colchicine, hypotonic solution and fixation (Bottura and Ferrari, 1960). The cytological preparations were analyzed by conventional staining or treated with trypsin solution to obtain GPG banding (Seabright, 1971). The mutations encountered were described according to ISCN 2005 (ISCN, 2005).

\section{RT-PCR}

The samples were processed by Ficoll Histopaque density gradient centrifugation (Sigma Diagnostics), and total RNA was extracted from the resulting leukocyte layer according to the Trizol (Invitrogen) protocol. For the reverse transcription reaction, $2 \mu \mathrm{g}$ RNA, dissolved in $20 \mu \mathrm{L}$ distilled water, was incubated for $10 \mathrm{~min}$ at $65^{\circ} \mathrm{C}$, and to this the following were added: $20 \mathrm{mM}$ Tris- $\mathrm{HCl}, 50 \mathrm{mM} \mathrm{KCl}, 5 \mathrm{mM} \mathrm{MgCl}, \mathrm{pH} 8.3,0.5 \mu \mathrm{g}$ Random Hexamers primers (Amersham Biosciences), $0.125 \mathrm{mM}$ dNTPs (Bio-Rad), $40 \mathrm{U}^{\mathrm{RNAse}}$ out $^{\mathrm{TM}}$ (Invitrogen), $200 \mathrm{U}$ M-MLV reverse transcriptase (Promega), in a final volume of $40 \mu \mathrm{L}$, which was incubated for $1 \mathrm{~h}$ at $37^{\circ} \mathrm{C}$ and then for $7 \mathrm{~min}$ at $65^{\circ} \mathrm{C}$.

RT-PCR was performed according to a standardized protocol by van Dongen et al. (1999), with modifications. In brief, $2 \mu \mathrm{L}$ cDNA was added to a mixture (final volume of 30 $\mu \mathrm{L}$ ) containing: $20 \mathrm{mM}$ Tris- $\mathrm{HCl}, \mathrm{pH} 8.3,50 \mathrm{mM} \mathrm{KCl}, 2.0 \mathrm{mM} \mathrm{MgCl}, 10 \mathrm{mM}$ of each internal primer (single) or $5 \mathrm{mM}$ of each control primer (GAPDH), $0.2 \mathrm{mM}$ dNTPs (Bio-Rad), and $1 \mathrm{U}$ Taq Polymerase (Invitrogen). The reaction was submitted to 35 cycles in a thermocycler (iCycler ${ }^{\mathrm{TM}} \mathrm{Bio}-\mathrm{Rad}$ ). The cycle time and the temperatures for denaturing, annealing and extension were respectively $94^{\circ} \mathrm{C}$ for $30 \mathrm{~s}, 65^{\circ} \mathrm{C}$ for $60 \mathrm{~s}$, and $72^{\circ} \mathrm{C}$ for $60 \mathrm{~s}$. A final extension was not carried out. For analysis, $15 \mu \mathrm{L}$ PCR product was applied to a $2 \%$ agarose gel. The thermocycler was programmed in the same way to detect all types of transcripts, and in every case the amplification was confirmed by shifted RT-PCR (van Dongen et al., 1999). The integrity of the cDNA was evaluated by amplification of the GAPDH gene.

Every sample that showed amplification of the control gene (GAPDH) was considered to be valid for analyses; those that also demonstrated a specific band for single-shifted RT-PCR were evaluated as positive cases. All cases were analyzed and reevaluated at least once, using positive control (REH cell line or cDNA from positive patient) and negative control (HL-60 cell line). The cell lines were kindly supplied by Dr. José Andres Yunes (Laboratório de Biologia Molecular do Centro Infantil de Investigações Hematológicas Dr. Boldrini, São Paulo, Brazil).

\section{RESULTS}

Among the 88 patients evaluated, 45 (51.14\%) were male and 43 (48.86\%) were female, and their ages at the time of diagnosis varied between 13 days and 17.6 years, with a median of 7.3 years.

The immunophenotyping analysis permitted the characterization of 72 cases as common ALL (B-precursor CD10+ ALL), 5 as pre-B-ALL (B-precursor CD10- ALL), 4 as pro-B-ALL (B-precursor CD10- ALL), and 7 as B-precursor ALL without definition of cellular maturation level.

Samples from every patient were submitted to molecular analysis for transcript identification. Table 1 shows the data referring to loss of material for molecular analyses; over the 
years, we can observe a downward trend in losses. An annual average of 29 cases analyzed was reached.

\begin{tabular}{|c|c|c|c|c|}
\hline & 2005 & 2006 & 2007 & Total \\
\hline Total registered & 30 & 36 & 36 & 102 \\
\hline Total analyzed & 24 & 31 & 33 & 88 \\
\hline Not analyzed & 6 & 5 & 3 & 14 \\
\hline$\%$ of loss & 20.00 & 13.89 & 8.33 & 13.73 \\
\hline
\end{tabular}

Table 2 indicates the frequencies obtained for each of the rearrangements investigated and their respective fluctuation in year by year frequency. Records show that rearrangement $M L L / A F 4$ was not detected during the period studied.

Table 2. Annual distribution of amplification frequencies of transcript fusions.

\begin{tabular}{|c|c|c|c|c|c|c|c|c|c|c|c|c|}
\hline & \multicolumn{2}{|c|}{2005} & \multicolumn{2}{|c|}{2006} & \multicolumn{2}{|c|}{2007} & \multicolumn{2}{|c|}{ Total } & \multicolumn{2}{|c|}{ Age (years) } & \multirow[t]{2}{*}{ Male/Female } & \multirow[t]{2}{*}{ Immunophenotyping } \\
\hline & $\mathrm{N}$ & $\%$ & $\mathrm{~N}$ & $\%$ & $\mathrm{~N}$ & $\%$ & $\mathrm{~N}$ & $\%$ & Variation & Median & & \\
\hline Total analyzed & 24 & 27.27 & 31 & 35.23 & 33 & 37.50 & 88 & 100.00 & 13 days- 17.6 & 7.3 & $45 / 43$ & \\
\hline$T E L / A M L 1$ & 0 & 0.00 & 3 & 9.68 & 7 & 21.21 & 10 & 11.36 & $2.2-16.11$ & 4.6 & $5 / 5$ & pre-B-ALL CD10+ \\
\hline$E 2 A / P B X I$ & 2 & 8.70 & 3 & 9.68 & 0 & 0.00 & 5 & 5.68 & $4.3-17.6$ & 10.7 & $4 / 1$ & pre-B-ALL CD10+ \\
\hline$B C R / A B L \mathrm{p} 190$ & 0 & 0.00 & 0 & 0.00 & 1 & 3.03 & 1 & 1.14 & 11.7 & - & $1 / 0$ & pre-B-ALL CD10+ \\
\hline Total amplified & 2 & 8.70 & 6 & 19.36 & 8 & 24.24 & 16 & 18.18 & $2.2-17.6$ & 5.4 & $10 / 6$ & \\
\hline
\end{tabular}

In addition, we studied two cases of unweaned infants, characterized with immunophenotype pro-B CD10- ALL, translocations $\mathrm{t}(9 ; 11) M L L / A F 9$ and $\mathrm{t}(11 ; 19) M L L / E N L A 1$, $M L L / E N L A 2$ and $M L L / E L L A$, the most frequent rearrangements involving the $M L L$ gene. The $M L L / E N L A 1$ transcript was identified as one of them.

Of the 44 cases with complete karyotypic analysis, 25 had a normal karyotype and 19 demonstrated chromosomal mutations, of which 11 showed hyperdiploidy, 4 hypodiploidy, 3 pseudodiploidy, and one constitutional trisomy 21 . One patient showed hyperdiploidy associated with a TEL/AML1 rearrangement (Table 3).

Table 3. Frequency distribution according to cytogenetic data.

\begin{tabular}{|c|c|c|}
\hline Results & Absolute frequency & Relative frequency \\
\hline Normal karyotype & 25 & $56.82 \%$ \\
\hline Chromosome anomaly & 19 & $43.18 \%$ \\
\hline Hyperdiploidy & $11^{*}$ & $25.00 \%$ \\
\hline Hypodiploidy & 4 & $9.10 \%$ \\
\hline Pseudodiploidy & 3 & $6.81 \%$ \\
\hline Trisomy 21 & 1 & $2.27 \%$ \\
\hline Total & 44 & $100.00 \%$ \\
\hline
\end{tabular}


The combined results of molecular and cytogenetic analysis are presented in Table 4 . We highlighted the non-detection of conclusive results in the majority of the cases studied and the non-agreement between molecular and cytogenetic findings. We also stress the occurrence of two cases, which showed a $\mathrm{t}(9 ; 22)(\mathrm{q} 34 ; \mathrm{q} 11)$ translocation and the absence of $B C R / A B L$ transcript. One patient showed hyperdiploidy associated with a TEL/AML1 rearrangement. These analyses showed a total of 36 chromosomal mutations among the 88 cases analyzed.

\begin{tabular}{lccc}
\multicolumn{1}{c}{ Table 4. Combined molecular and cytogenetic analysis } \\
\hline Anomalies & Molecular & Cytogenetic & \\
\hline $\mathrm{t}(9 ; 22) B C R / A B L$ & 1 & Not grown & 1 \\
$\mathrm{t}(1 ; 19) E 2 A / P B X 1$ & 5 & Not grown & 1 \\
& & Normal karyotype & 3 \\
$\mathrm{t}(12 ; 21)$ TEL/AML1 & 10 & Detection & 1 \\
& & Not grown & 3 \\
& & Hyperdiploidy & 3 \\
$\mathrm{t}(11 ; 19)$ MLL/ENLA1 & 1 & Not analyzed & 1 \\
Hyperdiploidy & - & Not grown & 3 \\
& & 47 to 50 & 1 \\
Hypodiploidy & - & $>50$ & 6 \\
Pseudodiploidy & - & 36 to 45 & 6 \\
Total & 17 & $\mathrm{t}(9 ; 22)(\mathrm{q} 34 ; \mathrm{q} 11)$ & 4 \\
\hline
\end{tabular}

*Includes the case that tested positive for TEL/AML1.

\section{DISCUSSION}

The frequency of $21.21 \%$ referring to the TEL/AML1 rearrangement, in 2007 (Table 2 ), is similar to previously published data for Brazilian children (20\%) (Magalhães et al., 2000), but it is below the $25 \%$ average reported in the literature (Abdelhaleem, 2007; Pui et al., 2008; Rubnitz et al., 2008). It is worth noting that the lower frequency of this fusion has also been observed in countries such as India (6\%) (Inamdar et al., 1998), Mexico (9.6\%) (Jimenéz-Morales et al., 2008), Argentina (11.6\%) (Alonso et al., 2006), Thailand (12\%) (Tiensiwakul, 2004), China (17.9\%) (Tsang et al., 2001), and Taiwan (19\%) (Liang et al., 1996). These values may reflect a lower incidence of pediatric B-ALL, a finding that supports Greaves' hypothesis, according to which children exposed to common infections during their first year of life, as is the case in less industrialized countries, have a better prepared immunological system. They are then less susceptible to the immunological stress of a later infection that would trigger molecular events subsequent to those that existed since neonatal life, leading to the stages of leukemogenesis (Greaves, 1988).

The improvement in medical assistance and socio-economic conditions in Brazil has resulted in the reduction of infant mortality rates caused by leukemia in the Federal District, but it has not led to an increased incidence of this disease to the level found in developed countries (Córdoba MS, unpublished data). We point out that the median reported here for positive cases of TEL/AML1 (4.6 years) is within this disease's identified occurrence peak (Greaves, 2006). However, the median age for leukemia occurrence in the group studied was 7.3 years (Table 3), and therefore later. 
As shown in Table 2, the frequency obtained for each transcript is not maintained over the years. It should be considered that there was a gradual decrease in the limited loss of available material for molecular analysis (Table 1). The frequency of transcript $B C R / A B L \mathrm{p} 190$ in 2007 (3.03\%) was similar to that in the literature (Rubnitz and Look, 1999; Abdelhaleem, 2007; Sastre et al., 2007). On the other hand, although potentially a random event, the values obtained for $E 2 A / P B X 1$ fusion in 2006 (8.70\%) and 2007 (9.68\%) were above the median reported, above the existing data in Brazil (Emerenciano et al., 2007) and among the highest ever registered (Jimenéz-Morales, 2008).

Differences in rearrangement frequencies have been observed between different ethnic groups (Pui et al., 2003; Aldrich et al., 2006; Jimenéz-Morales, 2008), suggesting the existence of a correlation between a population's gene pool and the occurrence of these chromosomal mutations. Considering the high miscegenation of Brazil's population (Pimenta et al., 2006), ethnic factors may also account for the findings.

It is possible that different factors act simultaneously in the etiology of B-ALL in childhood. With this in mind, we can consider that Greaves' hypothesis and the ethnic issue, among others, may contribute to the differences observed between the frequencies in occurrence of chromosomal rearrangements in this disease.

Although this is extremely infrequent (Attarbaschi et al., 2004), a concomitant finding of hyperdiploidy and cryptic translocation $\mathrm{t}(12 ; 21)$ was identified by the detection of the transcript of TEL-AML1 gene fusion by RT-PCR (Table 4).

There was no detection of transcript amplification for MLL/AF4 $\mathrm{t}(4 ; 11)$. The presence of genetic rearrangements involving the $M L L$ gene seems to be correlated to the non-expression of CD10 and immunophenotype pro-B, and is inversely associated with age, occurring at a higher frequency (50 to 80\%) among children younger than one year (Pui et al., 1990; van Dongen et al., 1999; Emerenciano et al., 2007). In the group studied, there were two cases of unweaned infants with this characterization. Over 25 chromosome loci are related to rearrangements involving the $M L L$ gene, with the most common translocations being $\mathrm{t}(4 ; 11)$, $\mathrm{t}(9 ; 11)$ and $\mathrm{t}(11 ; 19)$ (Rubnitz and Look, 1999), researched in both cases. The detection of $M L L / E N L A 1$ transcript in one of these cases confirms for the Federal District the frequency reported in the literature.

Two cases were identified in which the $\mathrm{t}(9 ; 22)(\mathrm{q} 34 ; \mathrm{q} 11)$ translocation was detected in cytogenetic analyses and in which no amplification of the corresponding transcript $(B C R /$ $A B L)$ was observed. It is possible that other genes that are different from $B C R$ and $A B L$, or at least from one of them, are not involved in the translocation, making it impossible for the hybrid gene $B C R / A B L$ to form. There are reports of the $B C R$ gene rearranging with other genes (Cirmena et al., 2008) and also the occurrence of submicroscopic deletions adjacent to breakpoints in $B C R$ and $A B L$, which could explain this finding (Table 4) (Moon et al., 2007; De Melo et al., 2008).

Among the patients with chromosomal anomalies (Table 3), hyperdiploidy $(\mathrm{N}=47$ to 57 ) was identified in $25 \%$ (11) of the cases analyzed. One of them occurred in association with the amplification of the TEL/AML1 transcript (Table 4).

Table 4 presents the results of the cytogenetic analysis concerning the presence of translocations that refer to the transcripts, showing that these do not agree with those from the molecular analysis. In 17 cases, the mutations were detected only in the molecular analysis. The lack of conclusive results, previously reported, makes it impossible to correlate cytoge- 
netic and molecular results. Cryptic mutations, the inability to obtain mitotic figures in ALL, and the often low percentage of clone cells in the group of metaphases analyzed are factors that make it difficult to perform good analyses. However, karyotypic analysis is essential in identifying numerical mutations and non-recurrent structural mutations.

Molecular analysis by RT-PCR was carried out in every sample, including those that were unsuitable for cytogenetic analysis, the cryopreserved ones and those with little cellularity. Furthermore, molecular analysis is more sensitive and more specific than cytogenetic as it identifies the presence of genetic rearrangements in samples where the cytogenetic result was negative, as well as the absence of important genetic rearrangements in patients with cytogenetically identical translocations, and cases in which the $\mathrm{t}(9 ; 22)$ translocation was detected in the absence of $B C R / A B L$ transcript (Table 4) (Pallisgaard et al., 1998; Rubnitz and Look, 1999). It is important to add that in a unique RT-PCR program different rearrangements may be detected simultaneously (van Dongen et al., 1999).

In the present analysis, molecular analysis by RT-PCR was shown to be an ideal tool for detecting hybrid transcripts, while cytogenetic research, a complementary technique, contributed to identifying numerical mutations and pseudodiploidy with no corresponding transcript.

The lower frequency for the TEL/AML1 transcript found in developing countries such as Brazil may be related to the lower incidence of leukemia, which would support Greaves' hypothesis.

\section{ACKNOWLEDGMENTS}

Research supported by Pronex/FAPDF/CNPq - Project 380/4. D.R. Mesquita was awarded a doctoral scholarship from FAPEAM, in the RH-POSGRAD modality.

\section{REFERENCES}

Abdelhaleem M (2007). Frequent but nonrandom expression of lymphoid markers on de novo childhood acute myeloid leukemia. Exp. Mol. Pathol. 83: 259-263.

Aldrich MC, Zhang L, Wiemels JL, Ma X, et al. (2006). Cytogenetics of Hispanic and White children with acute lymphoblastic leukemia in California. Cancer Epidemiol. Biomarkers Prev. 15: 578-581.

Alonso CN, Gallego MS, Alfaro EM, Rossi JG, et al. (2006). Caracterización molecular en leucemia linfoblástica aguda pediátrica en una institución hospitalaria/Pediatric lymphoblastic leukemia molecular characterization in a single institution. Hematología 10: 8-12.

Attarbaschi A, Mann G, Konig M, Dworzak MN, et al. (2004). Incidence and relevance of secondary chromosome abnormalities in childhood TEL/AML1+ acute lymphoblastic leukemia: an interphase FISH analysis. Leukemia 18: 1611-1616.

Bottura C and Ferrari I (1960). A simplified method for the study of chromosomes in man. Nature 186: 904-905.

Catovsky D, Matutes E, Buccheri V, Shetty V, et al. (1991). A classification of acute leukaemia for the 1990s. Ann. Hematol. 62: 16-21.

Cirmena G, Aliano S, Fugazza G, Bruzzone R, et al. (2008). A BCR-JAK2 fusion gene as the result of a t $(9 ; 22)(\mathrm{p} 24 ; \mathrm{q} 11)$ in a patient with acute myeloid leukemia. Cancer Genet. Cytogenet. 183: 105-108.

De Melo V, Milojkovic D, Marin D, Apperley JF, et al. (2008). Deletions adjacent to BCR and ABL1 breakpoints occur in a substantial minority of chronic myeloid leukemia patients with masked Philadelphia rearrangements. Cancer Genet. Cytogenet. 182: 111-115.

Emerenciano M, Koifman S and Pombo-de-Oliveira MS (2007). Acute leukemia in early childhood. Braz. J. Med. Biol. Res. 40: 749-760.

Greaves M (2006). Infection, immune responses and the aetiology of childhood leukaemia. Nat. Rev. Cancer 6: 193-203. Greaves MF (1988). Speculations on the cause of childhood acute lymphoblastic leukemia. Leukemia 2: 120-125.

Inamdar N, Kumar SA, Banavali SD, Advani S, et al. (1998). Comparative incidence of the rearrangements of TEL/AML1 
and ALL1 genes in pediatric precursor B acute lymphoblastic leukemias in India. Int. J. Oncol. 13: 1319-1322.

ISCN (2005). An International System for Human Cytogenetic Nomenclature. S Karger, Basel.

Jimenéz-Morales S, Miranda-Peralta E, Saldaña-Alvarez Y, Perez-Vera P, et al. (2008). BCR-ABL, ETV6-RUNX1 and E2A-PBX1: prevalence of the most common acute lymphoblastic leukemia fusion genes in Mexican patients. Leuk. Res. 32: 1518-1522.

Liang DC, Chou TB, Chen JS, Shurtleff SA, et al. (1996). High incidence of TEL/AML1 fusion resulting from a cryptic $\mathrm{t}(12 ; 21)$ in childhood B-lineage acute lymphoblastic leukemia in Taiwan. Leukemia 10: 1075-1088, 991-993.

Magalhaes IQ, Pombo-de-Oliveira MS, Bennett CA, Cordoba JC, et al. (2000). TEL-AML1 fusion gene frequency in paediatric acute lymphoblastic leukaemia in Brazil. Br. J. Haematol. 111: 204-207.

Moon HW, Chang YH, Kim TY, Oh BR, et al. (2007). Incidence of submicroscopic deletions vary according to disease entities and chromosomal translocations in hematologic malignancies: investigation by fluorescence in situ hybridization. Cancer Genet. Cytogenet. 175: 166-168.

Pallisgaard N, Hokland P, Riishoj DC, Pedersen B, et al. (1998). Multiplex reverse transcription-polymerase chain reaction for simultaneous screening of 29 translocations and chromosomal aberrations in acute leukemia. Blood 92: 574-588.

Pimenta JR, Zuccherato LW, Debes AA, Maselli L, et al. (2006). Color and genomic ancestry in Brazilians: a study with forensic microsatellites. Hum. Hered. 62: 190-195.

Pui CH and Crist WM (1994). Biology and treatment of acute lymphoblastic leukemia. J. Pediatr. 124: 491-503.

Pui CH, Crist WM and Look AT (1990). Biology and clinical significance of cytogenetic abnormalities in childhood acute lymphoblastic leukemia. Blood 76: 1449-1463.

Pui CH, Sandlund JT, Pei D, Rivera GK, et al. (2003). Results of therapy for acute lymphoblastic leukemia in black and white children. JAMA 290: 2001-2007.

Pui CH, Robison LL and Look AT (2008). Acute lymphoblastic leukaemia. Lancet 371: 1030-1043.

Raimond SC (1999). Cytogenetics of Acute Leukemias. In: Childhood Leukemias (Pui CH, ed.). Cambridge University Press, Memphis, 168-196.

Rubnitz JE and Look AT (1999). Molecular Genetics of Acute Lymphoblastic Leukemia. In: Childhood Leukemias (Pui CH, ed.). Cambridge University Press, Memphis, 197-218.

Rubnitz JE, Wichlan D, Devidas M, Shuster J, et al. (2008). Prospective analysis of TEL gene rearrangements in childhood acute lymphoblastic leukemia: a Children's Oncology Group study. J. Clin. Oncol. 26: 2186-2191.

Sastre DA, Argaraña CE, Heller VB, Gallo M, et al. (2007). An analysis of multiplex-PCR in the detection of BCR-ABL transcripts in hematological disorders. Genet. Mol. Biol. 30: 520-523.

Seabright M (1971). A rapid banding technique for human chromosomes. Lancet 2: 971-972.

Tiensiwakul P (2004). Cloning and sequencing of ETV6/RUNX1 (TEL/AML1) variant in acute lymphoblastic leukemia. Cancer Genet. Cytogenet. 149: 85-88.

Tsang KS, Li CK, Chik KW, Shing MM, et al. (2001). TEL/AML1 rearrangement and the prognostic significance in childhood acute lymphoblastic leukemia in Hong Kong. Am. J. Hematol. 68: 91-98.

van Dongen JJ, Macintyre EA, Gabert JA, Delabesse E, et al. (1999). Standardized RT-PCR analysis of fusion gene transcripts from chromosome aberrations in acute leukemia for detection of minimal residual disease. Report of the BIOMED-1 Concerted Action: investigation of minimal residual disease in acute leukemia. Leukemia 13: 1901-1928.

Wiemels JL, Ford AM, Van Wering ER, Postma A, et al. (1999). Protracted and variable latency of acute lymphoblastic leukemia after TEL-AML1 gene fusion in utero. Blood 94: 1057-1062.

Zago MA, Falcão RP and Pasquini R (2001). Hematologia: Fundamentos e Prática. Atheneu, São Paulo. 